\title{
IgM-rheumatoid factors cross-reactive with IgG and a cell nuclear antigen: immunopathological implications?
}

\author{
P. M. JOHNSON \\ From the Department of Immunology, University of Liverpool
}

SUMMARY The cross-reaction of IgM-rheumatoid factors (IgM-RF) with a cell nuclear antigen has $\underset{0}{\omega}$ been further investigated by immunofluorescence procedures. This reaction appears to be optimal $\dot{\sigma}$ at $\mathrm{pH} 8-9$, and fails to occur at $\mathrm{pH} 6 \cdot 5$. No evidence was obtained by immunofluorescence that $\mathcal{O}_{\infty}$ IgM-RF bound to the cell nuclear antigen fixes complement. It would appear that the nuclear reactivity of IgM-RF may be of limited immunopathological significance, though this reaction is of note in understanding the behavioural nature of rheumatoid factors.

Recent investigations have confirmed and extended an original observation by McCormick and Day ${ }^{1}$ that some rheumatoid factors (RF) appear to react with both IgG and a cell nuclear antigen. ${ }^{2} 3$ The occurrence of this cross-reacting antinuclear antibody (ANA) activity is high in isolated RF preparations, ${ }^{45}$ though it can be masked in the original seropositive serum and may often require purification of RF from serum for its manifestation. ${ }^{46}$ The relevant cross-reactive nuclear antigen is present in nuclei of normal cells from many species, including man, and would appear to require some concomitant presence of both DNA and core histone proteins for its antigenic representation. ${ }^{478}$

The apparent cross-reaction of RF with a cell nuclear antigen could be of immunopathological significance in RA, and this possibility has been explored by investigation of the $\mathrm{pH}$ and ionic strength requirements of this reaction, as well as of its complement-fixing potential.

\section{Materials and methods}

I GM-RF PREPARATIONS

IgM-RF preparations were isolated from 5 seropositive RA sera of high titre by affinity chromatography using immobilised heat-aggregated human IgG, as described previously. ${ }^{4}$ Isolated IgM-RF preparations were dialysed against phosphatebuffered isotonic saline (PBS), $\mathrm{pH} 7 \cdot 2$, concentrated

Accepted for publication 14 December 1979

Correspondence to $\mathrm{Dr}$ P. M. Johnson, Nuffield Wing, Medical School, University of Liverpool, PO Box 147, Liverpool L69 3BX. and stored frozen in small aliquots with addition of either $1 \%$ bovine serum albumin or $10 \%$ glycerol. Each aliquot of isolated IgM-RF preparations was thawed only once for immediate experimenta use. Two of the 5 whole sera used as source fơ IgM-RF gave ANA reactions when tested at 1:10َّ dilution in indirect immunofluorescence on cryostat sections of rat liver and kidney tissues. In contrast, all isolated IgM-RF preparations showed ANA activity when tested similarly at $50 \mu \mathrm{g} / \mathrm{ml}(50 \mathrm{mg} / \mathrm{l})$ as described and illustrated previously. ${ }^{4}$

IMMUNOFLUORESCENCE PROCEDURES

Indirect immunofluorescence on cryostat sections of rat liver and kidney tissues was performed as described previously ${ }^{4}$ with the following modifications according to the experimental design. The $\mathrm{pH}$ sensitivity of the ANA reaction of isolated IgM-RF preparations was investigated by performing the first-layer antibody-binding reaction and washing 욱 wholly in PBS whose $\mathrm{pH}$ had been adjusted appro- $\rightarrow$ priately to points within the range $\mathrm{pH} 5 \cdot 0-10 \cdot 0$. by addition of either $0.5 \mathrm{M} \mathrm{HCl}$ or $0.5 \mathrm{M} \mathrm{NaOH}$. In some experiments $0.05 \mathrm{M}$ Tris- $\mathrm{HCl}$ or $0.05 \mathrm{M}$ Tris- $\mathrm{NaOH}$ buffers were also employed, both with $\mathrm{N}$ $0.1 \mathrm{M} \mathrm{NaCl}$ added. The subsequent second-layer $\mathrm{N}$ staining reaction with an appropriate dilution of fluorescein isothiocyanate (FITC)-conjugated anti- $\bullet$ human Ig or IgM (Wellcome Reagents Ltd., Beckenham, Kent) and washing were performed wholly in PBS, pH 8.0.

The ionic strength sensitivity of the ANA reaction of isolated IgM-RF preparations was investigated by performing the first-layer antibody-binding 
reaction and washing wholly in $\mathrm{PBS}, \mathrm{pH} 8 \cdot 0$, at $0 \cdot 1,0 \cdot 33,1 \cdot 0,3 \cdot 0$, and $10 \cdot 0 \times$ isotonic molarity. As before, the subsequent second-layer FITCconjugated antibody-staining reaction and washing were performed wholly in PBS, $\mathrm{pH} 8 \cdot 0$.

Complement fixation following the reaction of IgM-RF with a cell nuclear antigen was investigated by exposure of cryostat sections of rat liver tissue to $0 \cdot 2-0 \cdot 5 \mathrm{mg} / \mathrm{ml}(200-500 \mathrm{mg} / \mathrm{l})$ isolated IgM-RF followed, after washing, with appropriate dilutions of fresh normal guinea-pig serum (GPS). Negative control experiments were performed with PBS alone (rather than IgM-RF) in the first layer, or heatinactivated GPS (rather than fresh GPS) in the second layer. Positive control experiments were performed with dilutions of various IgM-ANA-positive seronegative sera rather than dilutions of isolated IgMRF in the first layer. Sections were stained with an appropriate dilution of FITC-conjugated antiguinea-pig C3 serum (Nordic Immunological Laboratories, Tilburg, The Netherlands), and all washing and dilution steps were performed in PBS,

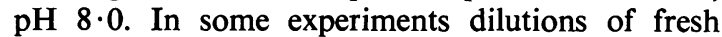
normal human serum were used as a complement source rather than GPS, and sections were then stained with FITC-conjugated antihuman C3c serum (Behringwerke AG, Marburg, Germany).

\section{Results}

All isolated IgM-RF preparations showed optimal reactivity with a cell nuclear antigen in immunofluorescence when the binding reaction was performed in buffers at $\mathrm{pH} 8-9$. No positive reaction was noted at $\mathrm{pH} 6 \cdot 5$. A typical $\mathrm{pH}$ sensitivity profile for the ANA activity of IgM-RF is given in Table 1 . This contrasts with the optimal $\mathrm{pH}$ profile for whole IgM-ANA-positive RF-negative sera, which was determined to be $\mathrm{pH} 6 \cdot 0-8 \cdot 5$.

All isolated IgM-RF preparations showed optimal reactivity with a cell nuclear antigen in immunofluorescence when the reaction was performed in

Table $1 p H$ sensitivity of cell nuclear reactivity of an isolated IgM-RF preparation $(0.2 \mathrm{mg} / \mathrm{ml}(200 \mathrm{mg} / \mathrm{l}))$

\begin{tabular}{ll}
\hline $\begin{array}{l}\text { pH of antibody-binding } \\
\text { reaction buffer }\end{array}$ & Titre of ANA activity \\
\hline 5.0 & - \\
$5 \cdot 5$ & - \\
6.0 & - \\
6.5 & - \\
7.0 & 8 \\
7.5 & 18 \\
8.0 & 16 \\
8.5 & 16 \\
9.0 & 16 \\
9.5 & 8 \\
10.0 & 2 \\
\hline
\end{tabular}

Table 2 Ionic strength sensitivity of cell nuclear reactivity of an isolated IgM-RF preparation $(0.2 \mathrm{mg} / \mathrm{ml}(200 \mathrm{mg} / \mathrm{l}))$

\begin{tabular}{lc}
\hline $\begin{array}{l}\text { Molarity }(M) \text { of antibody- } \\
\text { binding reaction buffer }\end{array}$ & Titre of ANA activity \\
\hline 0.015 & 4 \\
0.05 & 32 \\
0.15 & 16 \\
0.45 & 4 \\
1.5 & 2 \\
\hline
\end{tabular}

$0.05-0.15 \mathrm{M}$ buffer. A typical ionic strength sensitivity profile for the ANA activity of IgM-RF is given in Table 2. Similar optimal profiles for ionic strength were observed with whole IgM-ANApositive RF-negative sera.

Evidence for complement fixation from GPS by IgM-RF bound to the cell nuclear antigen was sought by immunofluorescence. These experiments were consistently negative whereas most whole IgMANA-positive RF-negative sera studied analogously showed clear complement fixation, manifest by positive nuclear staining for guinea-pig $\mathrm{C} 3$. Controls stained for human IgM rather than guinea-pig C3, after treatment of tissue sections with IgM-RF followed by GPS, showed that treatment with dilutions of GPS did not dissociate all IgM-RF from the nuclear antigen.

\section{Discussion}

In the absence of any data yet available comparing binding affinities of the reactions of RF with IgG and a cell nuclear antigen the immunopathological significance of the ANA activity of RF must be assessed by investigation of its optimal reaction conditions and of any biological sequelae following this reaction. Previous work has shown that the ANA activity of RF may often appear masked in whole seropositive serum, ${ }^{46}$ suggesting that this cross-reacting antibody specificity might be of significance only in a serum-depleted milieu such as following phagocytosis of RF-containing complexes. The present study has indicated a displacement to alkaline $\mathrm{pH}$ of the optimal reaction conditions for cell nuclear reactivity of IgM-RF compared with whole IgM-ANA-positive RF-negative sera. This could reflect either an unusual lability of the relevant cell nuclear antigenic structure to acidic $\mathrm{pHs,}$ even to $\mathrm{pH} 6 \cdot 5$, or an unusual ionic contribution to the antigen-antibody interaction. Previous studies ${ }^{4} 8$ have indicated that the relevant cell nuclear antigen may be dependent on the presence of both the strongly anionic and cationic macromolecular components in the nuclear complex, and the unusual 
alkaline optimal $\mathrm{pH}$ of nuclear reactivity of $\mathrm{RF}$ may be clarified when further studies have defined the nature of the relevant cell nuclear antigen. The optimal ionic strength for cell nuclear reactivity of IgM-RF, at or below isotonic molarity, supports there being a significant ionic contribution to this interaction.

No evidence has been gained by immunofluorescence that IgM-RF bound to the cell nuclear antigen can fix complement. The above data taken together would indicate that the nuclear reactivity of IgM-RF may be of limited immunopathological significance in that the reaction $(a)$ does not appear to result in complement fixation, $(b)$ is optimal at pH 8-9, and (c) may often be inhibited by other serum components.

Finally, it is of note that IgM-rheumatoid factors in RA show a pronounced degree of antigenic homogeneity in their own immunoglobulin structure in terms of light-chain antigens, ${ }^{9}$ heavy-chain variable region subgroup antigens, ${ }^{10}$ and idiotypic antigens. ${ }^{11}$ This restriction of molecular heterogeneity may be expected for antibody populations resulting from a chronic immunisation procedure. However, in marked contrast, IgM-rheumatoid factors in RA show a pronounced degree of antibody heterogeneity in terms of specificity for antigens on $\mathrm{IgG}$ from human and other species ${ }^{12}$ as well as demonstrating certain unexpected cross-reactions. The most notable cross-reaction is that described with a cell nuclear antigen, but apparent cross-reactions with the haptenic dinitrophenyl and trinitrophenyl groups and with bacterial peptidoglycan have also been described. ${ }^{13} 14$ The reasons for this behavioural contrast of IgM-RF in RA remain unexplained.

I thank Carole White and Peter Brown for excellent technical assistance during parts of this study.

\section{References}

1 McCormick J N, Day J. The association of rheumatoid factor with anti-nuclear factor activity. Lancet 1963; ii: $554-7$.

2 Hannestad K, Johannessen A. Polyclonal human antibodies to IgG (rheumatoid factors) which crossreact with cell nuclei. Scand J Immunol 1976; 5: 541-7.

3 Hannestad K. Certain rheumatoid factors react with both IgG and an antigen associated with cell nuclei. Scand J Immunol 1978; 7: 127-36.

4 Johnson $\mathbf{P}$ M. IgM-rheumatoid factors cross-reactive with IgG and a cell nuclear antigen: apparent 'masking' in original serum. Scand J Immunol 1979; 9: 461-6.

5 Tipton C, Peebles C, Joslin F, Tan E M. Characteristics of anti-nuclear antibodies in rheumatoid arthritis. Arthritis Rheum 1979; 22: 657 (abstract).

6 Johnson P M. Stimuli for anti-IgG antibody production in rheumatoid arthritis. In: Panayi $\mathbf{G ~ S}$, Johnson $\mathbf{P} \mathbf{M}$, eds. Immunopathogenesis of Rheumatoid Arthritis. London: Reedbooks, 1979: 45-50.

7 Hannestad K, Stollar B D. Certain rheumatoid factors react with nucleosomes. Nature 1978; 275: 671-3.

8 Agnello V. Pitfalls in the use of biologic reagents for the detection of immune complexes. In: Peeters $\mathrm{H}$, ed. Protides of the Biological Fluids, 26th Colloquim, 1978. 1979: 15-9. Pergamon Press.

9 Carson D A, Lawrence S. Light chain heterogeneity of 19S and 7S anti- $\gamma$-globulins in rheumatoid arthritis and subacute bacterial endocarditis. Arthritis Rheum $1978 ; 21$ : $438-40$.

10 Førre $\varnothing$, Johnson P M, Natvig J B. A study of the variable heavy chain $\left(\mathrm{V}_{\mathrm{H}}\right)$ regions in human polyclonaf IgM rheumatoid factors. Scand J Rheumatol 1977; 6공 113-7.

11 Førre $\varnothing$, Doblaug J H, Michaelsen T E, Natvig J B. Evidence of similar idiotypic determinants on different rheumatoid factor populations. Scand J Immunol 1979; 9: 281-9.

12 Johnson P M, Faulk W P. Rheumatoid factor: its nature, specificity and production in rheumatoid arthritis. Clin Immunol Immunopathol 1976; 6: 414-30.

13 Hannestad K. Monoclonal and polyclonal $\gamma \mathrm{M}$-rheumatoid factors with anti-di and anti-trinitrophenyl activity. Clin Exp Immunol 1967; 4: 555-78.

14 Bokisch V A, Chaio J W, Bernstein D, Krause R M. Homogeneous rabbit $7 \mathrm{~S}$ anti-IgG with antibody specificity for peptidoglycan. J Exp Med 1973; 138: 1184-93. 